\title{
Interpreting colonialism, edited by Byron R. WELLS and Philip STEWART
}

\section{Paola Sosso}

\section{QpenEdition \\ Journals}

\section{Edizione digitale}

URL: http://journals.openedition.org/studifrancesi/33241

DOI: 10.4000/studifrancesi.33241

ISSN: 2421-5856

\section{Editore}

Rosenberg \& Sellier

\section{Edizione cartacea}

Data di pubblicazione: 1 décembre 2005

Paginazione: 644

ISSN: 0039-2944

Notizia bibliografica digitale

Paola Sosso, «Interpreting colonialism, edited by Byron R. wells and Philip steWART», Studi Francesi [Online], 147 (XLX | III) | 2005, online dal 01 novembre 2015, consultato il 19 avril 2021. URL: http:// journals.openedition.org/studifrancesi/33241 ; DOI: https://doi.org/10.4000/studifrancesi.33241

Questo documento è stato generato automaticamente il 19 avril 2021.

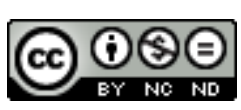

Studi Francesi è distribuita con Licenza Creative Commons Attribuzione - Non commerciale - Non opere derivate 4.0 Internazionale. 


\section{Interpreting colonialism, edited by Byron R. WELLS and Philip STEWART}

Paola Sosso 


\section{NOTIZIA}

Interpreting colonialism, edited by Byron R. wELLS and Philip STEWART, Oxford, Voltaire Foundation, ("SVEC 2004", 9), 2004, pp. 000.

1 Il volume, denso e articolato, comprende vari interventi, tra i quali solo alcuni riguardano l'area francese. Nella prima sezione, dal titolo «Représentations» si trova lo studio di Driss AISSAOUI che analizza L'image de l'Autre dans le Journal de voyage de Robert Challe, (pp. 3-15). L'autore mostra come Challe assuma un atteggiamento paradossale, che va dalla xenofobia fino a una vera e propria apertura nei confronti delle culture diverse: il viaggio alle Indes orientales conduce il pensiero di Challe dal pregiudizio al riconoscimento dell'altro, in un percorso ben ricostruito in questo articolo. Fabienne Sophie CHAUDELOT si concentra invece sui Prolégomènes à un anti-colonialisme futur: Histoire des deux Indes et Supplément au Voyage de Bougainville de Diderot (pp. 16-33): l'autrice propone una lettura in parallelo di questi due testi (per quanto riguarda l'Histoire, solo i brani riconducibili alla penna di Diderot), partendo da alcuni elementi teorici, economici e politici col fine di mettere in evidenza le affinità del pensiero diderotiano con la teoria post-coloniale contemporanea. Le due sezioni successive «Mercantilism» e «Religion and ideology» riguardano per lo più l'ambito spagnolo, inglese, o aree extra-europe, mentre nell'ultima parte, dal titolo "Slavery», l'articolo di Lynn FESTA (Tropes and chains: figures of exchange in eighteenth-century depictions of the slave trade, pp. 322-344) fornisce un resoconto delle figure usate nel descrivere, con fini diversi, il commercio degli schiavi, mostrano come il linguaggio legato allo "scambio" prevalga anche nei testi che intendono difendere i diritti delle persone oppresse dalla schiavitù: lo studio si concentra per lo più sull'ambito anglosassone, con qualche cenno all'Encyclopédie, a Raynal, Monteqeuieu e Diderot. 